\title{
Erratum to: A Case of Ruptured Adult Embryonal Sarcoma of the Liver with Excellent Outcome After Neoadjuvant Chemotherapy
}

\author{
Saurabh Zanwar ${ }^{1} \cdot$ Mahesh Goel $^{2} \cdot$ Shraddha Patkar $^{2} \cdot$ Anant Ramaswamy $^{1} \cdot$ \\ Nitin Shetty ${ }^{3} \cdot$ Mukta Ramadwar $^{4} \cdot$ Vikas Ostwal $^{1}$
}

Published online: 29 October 2016

(C) Springer Science+Business Media New York 2016

\section{Erratum to: J Gastrointest Canc}

DOI 10.1007/s12029-016-9877-6

The original version of this article unfortunately contained a mistake. The age of the patient in the first sentence of the first paragraph under the Case Summary section was incorrectly mentioned as 2 years, which is actually 25 years. The sentence should read:

A 25-year-old gentleman with no known medical comorbidities presented to his primary physician with complaints of right hypochondriac pain of 2 months duration.

The original article was corrected.

The online version of the original article can be found at http://dx.doi. org/10.1007/s12029-016-9877-6.

Vikas Ostwal

dr.vikas.ostwal@gmail.com

1 Department of Medical Oncology, Tata Memorial Centre, Mumbai, India

2 Department of Surgical Oncology, Tata Memorial Centre, Mumbai, India

3 Department of Radiodiagnosis, Tata Memorial Centre, Mumbai, India

4 Department of Pathology, Tata Memorial Centre, Mumbai, India 